Portland State University

PDXScholar

Fall 12-10-2013

\title{
How Does Student Understanding of a Concept Change Throughout a Unit of Instruction? Support Toward the Theory of Learning Progressions
}

Brian Jay Dyer

Portland State University

Follow this and additional works at: https://pdxscholar.library.pdx.edu/open_access_etds

Part of the Curriculum and Instruction Commons, Educational Methods Commons, and the Junior High, Intermediate, Middle School Education and Teaching Commons Let us know how access to this document benefits you.

\section{Recommended Citation}

Dyer, Brian Jay, "How Does Student Understanding of a Concept Change Throughout a Unit of Instruction? Support Toward the Theory of Learning Progressions" (2013). Dissertations and Theses. Paper 1528. https://doi.org/10.15760/etd.1527

This Thesis is brought to you for free and open access. It has been accepted for inclusion in Dissertations and Theses by an authorized administrator of PDXScholar. Please contact us if we can make this document more accessible: pdxscholar@pdx.edu. 
How Does Student Understanding of a Concept Change Throughout a Unit of Instruction? Support Toward the Theory of Learning Progressions.

by

Brian Jay Dyer

A thesis submitted in partial fulfillment of the requirements for the degree of

Master of Science in Teaching

in

General Science

Thesis Committee:

Melissa Potter, Chair

Cary Sneider

Liza Finkel

Portland State University

2013 


\begin{abstract}
This study documented the changes in understanding a class of eighth grade high schoollevel biology students experienced through a biology unit introducing genetics. Learning profiles for 55 students were created using concept maps and interviews as qualitative and quantitative instruments. The study provides additional support to the theory of learning progressions called for by experts in the field. The students' learning profiles were assessed to determine the alignment with a researcher-developed learning profile. The researcher-developed learning profile incorporated the learning progressions published in the Next Generation Science Standards, as well as current research in learning progressions for $5-10^{\text {th }}$ grade students studying genetics. Students were found to obtain understanding of the content in a manner that was nonlinear, even circuitous. This opposes the prevailing interpretation of learning progressions, that knowledge is ascertained in escalating levels of complexity. Learning progressions have implications in teaching sequence, assessment, education research, and policy. Tracking student understanding of other populations of students would augment the body of research and enhance generalizability.
\end{abstract}


Table of Contents

Abstract $\quad$ i

List of Tables $\quad$ iii

List of Figures $\quad$ iv

Introduction $\quad 1$

Literature Review 3

$\begin{array}{ll}\text { Method } & 17\end{array}$

$\begin{array}{ll}\text { Results } & 27\end{array}$

$\begin{array}{ll}\text { Discussion } & 33\end{array}$ 


\section{List of Tables}

$\begin{array}{ll}\text { Table 1: Experimental Design } & 17\end{array}$

Table 2: Propositions \& Associated Classroom Activities 24

Table 3: Concept Map Timing 25

Table 4: Percentages of Valid Propositions Overall 30 


\section{List of Figures}

Figure 1: Example Learning Profile

Figure 2: Student Profiles

28. 29

Figure 3: Percentages of Valid Propositions Overall

Figure 4: List of Propositions 


\section{Chapter 1: Introduction}

A learning progression is defined as a "sequence of successively more complex ways of reasoning about a set of ideas" (p. 3 NAGB, 2005). Shavelson (2009) state that "both substantive psychological theory building and research into learning progressions are needed urgently for the most important of science conceptions in the curriculum" ( $p$. $18)$.

At present, learning progression theory posits that students' understanding develops along a logical pathway, characterized by more complex understanding building on simpler ideas. In a challenge to conventional learning progression theory, Shavelson (2009) points out that students may not learn that way, and in fact, their learning might be complex and idiosyncratic. Consequently, he calls for collaboration between teachers and researchers to study the detailed pathways that characterize learning within students during a unit of study. This study takes up Shavelson's challenge to the conventional theory by determining if student learning conforms to the expectations of learning progression theory, or if he is correct, that learning is better characterized as "wandering through a complex memory network composed of bits and pieces of information" (p. 18).

The study was a quasi-experimental design where the unit of instruction is the independent variable and the dependent variable is the set of learning progressions supplied by students depicted on concept maps. Based on Shavelson's work, I expect students to produce concept maps that reveal nonlinear pathways to understanding as they approach mastery of a concept.

There are two approaches to learning progressions as described by Shavelson et al. (2009). There is the curriculum and instruction approach that speaks directly to planning, 
testing, and standards in education across grade bands. There is also the cognitive and instruction approach that begins with psychological analysis of cognition. "Students will construct an explanation that is context dependent and draws on bits and pieces of knowledge embedded in a memory network to reconstruct their knowledge and provide an explanation" (p 14).

The outcome of the latter is a map of the changes in cognition as students learn about a concept. This type of learning progression provides a picture of what changes occur during instruction and has implications for the creation and implementation of curriculum, teaching, and assessment (Shavelson, 2009).

Following this reasoning, changes in student understanding were represented using concept maps, a technique developed by Novak (1991). A concept map is a graphic representation of students' conceptual understanding in the form of propositions. Propositions associate concepts together as relationships; as understanding of a concept changes, the evolution can follow pathways that are non-linear. Concept maps allow a student to employ linkages to illustrate her or his understanding of relationships among concepts that do not necessarily follow a step-by-step linear process. Instead, they allow for the possibility of creating propositions that are connected in ways not readily seen in a narrative with a beginning, middle, and end.

This study was designed to explore the theory of learning progressions by following students' changes in understanding across a unit of study in a biology curriculum. Students' understanding of genetics was shown using concept maps prior to and after instruction, as well as critical junctures over six weeks. 


\section{Chapter 2: Literature Review}

Overview

The current thinking on learning progressions favors a step-wise fashion to explain learning, a change of understanding that begins with simple concepts and increases in complexity. This interpretation of learning progressions is thought to follow trajectories that are empirical, testable (Corcoran, Mosher, \& Rogat 2009). Understanding is seen as building in complexity from a simple, central concept and adding layers of complexity afterward. An alternative view is that the pathways to learning are meandering as new learning is associated with past experiences. The meandering is due as much from the context of instruction as it is dependent on a learner's individuality (Shavelson 2009). The Next Generation Science Standards, developed by the National Research Council and Achieve Inc., has built in learning progressions. These escalated learning progressions are used to develop a smaller set of core ideas in the Next Generation Science Standards across grade bands K-12 (Achieve, Inc. 2013). This literature review will: a.) explain different definitions of learning progressions, b.) provide a justification for considering students' misconception when developing learning progressions, and c.) provide a rationale for using concept maps as an instrument to measure changes in understanding. Finally, a summary provides a connection between the literature presented and the research question.

\subsection{Learning Progressions, hypothetical changes in understanding}

Corcoran, Mosher, and Rogat (2009) of the Center on Continuous Instructional Improvement, Columbia University composed a report whose purpose was to describe the work done to date on learning progressions, address issues and debates, and identify 
further investments in future development and implementation. A panel composed of 21 leaders in the field convened and reviewed 22 proposed learning progressions. The progressions represented K-15 grade bands and all core disciplines in science education. The authors cited Taking Science to School (NRC, 2007), "Learning progressions in science are empirically grounded and testable hypotheses about how students' understanding of, and ability to use, core scientific concepts and explanations and related scientific practices grow and become more sophisticated over time, with appropriate instruction." The authors propose that the testable nature of learning progressions provides a potential solution to the federal government's dilemma of how to allocate Title I education funds. The distribution of which is largely contingent on states' ability to set goals for all students' success. It is thought that the more that is known about how students learn, the fewer and clearer standards will be needed.

Moving forward with new national standards, the authors are prescient to the need for research based standards. Although presently evidence for learning progressions' usefulness and validity is not substantial enough to fully replace standards in American schools. Construct validity for learning progressions is intended to calibrate the learning pathways students experience, given appropriate instruction. Ultimately, consequential validity must also be established through the comparison of students' achievement taught with and without learning progressions. The authors propose that progressions could describe what most students are capable of achieving; as well as, in what order these scientific concepts would best be instructed.

The existence of an optimal learning progression for all students is not assumed by the authors. The likely influences in the variation of learning progressions are thought 
to be differences in instruction, as well as experimental design. Moving forward, the authors recommend further research on the interrelatedness of learning progressions experienced by students throughout their education across all subjects. Also, assessments are needed that measure student performance aligned with key steps in the progressions.

Shavelson was invited to provide a critical review of the current line of thinking around learning progressions . In 2009, Shavelson warns researchers to the hypothetical and under-researched state of learning progressions, and the vulnerability their development has to data fitting, thereby undermining validity. He concludes with recommendations for further research in the field. For example, he suggests teachers and researchers collaborating on action research and teaching experiments to provide the evidence and experience necessary to refine and validate learning progressions.

Shavelson (2009) brings attention to the controversy of learning progressions. A learning progression is a sequence of reasoning regarding concepts that are not developmentally inevitable, but dependent upon instruction interacting with students' acquired experience. Shavelson points to inadequacies in the emerging field. Primary among them is the lack of long term longitudinal studies following individual students, tracking their learning over time. As well as the lack of research supporting the testable validity of learning progressions used to develop units of study. Learning progressions, to date, have been approached in two distinct ways. In one case, curriculum and instruction inform the progression directly; content is the focus and instruction is the context. The second approach focuses on cognition and psychological theories of development. Again, instruction is the context, but this second approach begins with a psychological analysis 
of what it means to understand the content. Both have been used to create learning progression increasing in levels of complexity, a linear path.

Shavelson speaks to basic principles of cognitive science that lend nicely to learning progressions: knowing \& doing are part of a cognitive network, and the reconstructive nature of memory. He goes on to say that if a student's conceptions are linear they will fit nicely within the second approach to learning progressions where cognition is the focus. But assuming that some students' understanding is less sequential and therefore will look more context dependent. Context, in this sense, that derives from instruction and a students' prior knowledge. To investigate the curriculum and instruction approach, Shavelson suggests partnering teachers with researchers to work on validating particular progressions and making those findings public. Furthermore, he warns that there is a possibility of fitting the data to favorable circumstances and one ought to look to disconfirmation in support of the evidence for learning progressions.

Developing learning progressions could yield tremendous positive results in education reform: decreasing the need for numerous, fact-driven standards. However, the use of learning progressions in the classroom is under-documented. In the following paper, a teacher proposes a learning progression for the acquisition of science process skills and reports on her progress.

Paysnick (2010) reports positive effects of learning progressions in "Finding learning beneath the surface: Monitoring student progress with Science Practice Learning." The efficacy of science inquiry as a tool for instruction is only as good as its measure, she states. Learning progressions serve as formative assessment for this instructional practice. She argues that science practices: observation, measurement, 
analysis, modeling, etc., should not be taught in isolation outside of inquiry. Instead paying heed to a student's development should be considered and prior instruction made to fit within emerging concepts. Paysnick developed a learning progression to measure student performance, understanding, and utilization of science practices ranging from pre-beginner to proficient. The learning progression was developed in the format of a rubric used to quantify the students individually and as a class. The data she accumulated informed her instruction and led to several modifications in the development of activities and led to differentiation for students of varying performance levels. Furthermore, the researcher found that students' progression was often not linear and that more attention should be paid to alternative conceptions as a means to reach more valid understandings. The learning progressions allowed the researcher to observe learning that slowly develops over time and encourages students to become astute observers.

Catley et al. (2005) propose a learning progression for the life sciences focusing on evolution. The team followed the aforementioned curriculum and instruction approach posing "big questions" within the subdiscipline and following a logical analysis of the subject. Their research adds to the body of work validating learning progressions in the sciences. The occurrence and persistence of alternative conceptions among students shows individual students' changes in understanding and supports Shavelson's position that learning progression are not developmentally inevitable.

Catley et al. (2005) reported the importance of identifying developmental corridors for students learning evolution concepts. These developmental corridors identify core concepts early on and, across grade bands, refines and elaborates upon them. The new knowledge is made accessible and practical to the learner while still providing 
challenges that foster deeper understanding in later grades. Using this criterion, learning progressions were drafted for the concepts in evolution. The authors relied upon The American Association for the Advancement of Science and NRC standards documents. Key concepts to evolution were determined through the consideration of the question, "How is biological diversity generated, maintained, and changed?" The concept list includes: diversity, structure-function, variation, geological processes, mathematical tools, and forms of argument. The authors envisioned learning progressions that would not treat the material in isolation, instead the concepts would be introduced early, in grade 2, and revisited several times over, on to grade 12. Each year the relationships between the concepts would be emphasized and refined. A review of the literature allowed the authors to categorize misconceptions by concept. Among many, the authors found that students related speciation to spontaneous generation and essential kinds. Students also posed a teleological view that evolution is process with an ultimate outcome (sometimes considered to be humankind). There was a measurable persistence to the misconceptions occurring at relative frequencies that did not change through the grades $2,5,8$, and 12 . These misconceptions, alongside extant AAAS and NRC documents, guided the authors to create a learning progression spanning grades $2-12$. The authors drafted the progressions with rationale, big ideas from each of the key concepts, and learning performance tasks associated to each of the key concepts.

\subsection{Misconceptions, prior knowledge as context}

Understanding how educators can define learning progressions is important, but we must also understand the role students' own thinking can inform how we develop learning progressions. Students' misconceptions, in particular, can play an important role 
in the process of understanding new concepts (Sneider 1998). Each students' unique development of understanding supports Shavelson's ideas about learning progressions because they are not treated as developmentally inevitable. The preceding paper reported on the persistence of misconceptions and recommends that the relationships between concepts should be emphasized. The literature shows that persistence of misconceptions is common across the disciplines of science, particularly where abstractions of immense scales of size and time are concerned.

"Learning About Seasons: A Guide for Educators and Curriculum Developers" (Sneider et al. 2011) reviews forty-one studies related to students' acquisition of valid conceptions in regard to seasons and their causes. The scope of the studies reviewed included more than a thousand learners and consisted of pre and post-tests, interviews and questionnaires, evaluating students' concept of seasons. The researchers report that, although seen as elementary, the scientific concept of the seasons spans multiple disciplines and involves the teaching of abstract concepts, such as light and energy. The most common misconception documented was of the idea Earth's seasons were caused by an elliptical orbit which caused the Earth to be physically closer to the Sun during summer. Described in the 1989 video, "A Private Universe," many Harvard graduates and a professor miss the mark in their explanations. The author points to emerging patterns in the proliferation of studies on the subject. Across many countries, students of various education levels and ages give similar initial, alternative, and synthetic hypotheses. The research elucidates the appropriate stages at which students are capable of grasping various concepts and informs the criteria for assessing student understanding. The review includes a proposed learning progression drawing from the inferences of the 
collected works. The progression reflects the research of how students actually learn, not a sequence of disciplinary knowledge based on logical analysis alone. A concept map was constructed in grade bands outlining the learning progression from grade four to twelve. The authors conclude that the concept of seasons is difficult to teach due to the depth of understanding involved, but perhaps it is that difficulty that makes it important to do so.

The role misconceptions play in learning has been a topic of much research. Sadler (1998) proposes that misconceptions can play an important role in the process of understanding new concepts. While they may be persistent, the use of misconception in the planning of curriculum is valuable if they are seen as "stepping stones."

In his study published in 1998, Sadler sought to employ psychometric modeling to rank potential alternative conceptions on a multiple choice test. The study described the unusual trend that instruction tends to support alternative conceptions before the scientifically correct conceptualization is adopted. The purpose of the study was to explore the interplay between mastery of a concept and the "stepping stones" of alternative conceptions. The researchers developed an instrument called the Project STAR Astronomy Concept inventory. They tested 1250 students with pre and posttests. In the published study, the researchers created a profile of three sample questions from the 47-item instrument. The analysis involved an Item Response Theory model that described the probability of choosing a correct answer plotted against overall ability on the test. The model interpreted a student's likelihood to guess on an item versus choosing an incorrect answer, indentified as an alternative conception. Alternative conceptions were found to be prevalent at certain ability levels, and in many cases exceeded in 
popularity compared to the estimation of guessing or the correct answer. The author concluded that multiple choice tests are very useful assessment tools when coupled with psychometric models. Conceptual changes take place over time. The author recommends more research in documenting these changes in understanding across grade bands, as well as units of instruction. As seen in students understanding of the change in seasons; although it is introduced at grade five or six, mastery of the concept is not achieved until college. Moreover, the author concludes that new curricula should treat and discuss alternative conceptions as stepping stones toward mastery, not merely as errors.

Alternative conceptions, or stepping stones, in learning play an important role in developing mastery for students. The prior knowledge of students is highly individualized and intersects with instruction and the acquisition of new knowledge in a context dependant manner. There is no one correct order that a learning progression follows; they are not developmentally ingrained.

\subsection{Concept Maps, an instrument measuring changes in understanding}

Novak and Musandra (1991) conducted "A Twelve-Year Longitudinal Study of Science Concept Learning" which followed a set of students from grades one and two to grade twelve. The researchers used qualitative and quantitative measures of abstract concepts. Moreover, the study pioneered the development of concept maps as a tool and illustrates the "tenacious persistence of misconceptions acquired early in learning" (p. 135). A sample of 191 students was offered audio-tutorial instruction at grades one and two, a similar sample of 48 students were not provided with the tutorial. Interviews measuring science conceptions and misconceptions were conducted with both groups 
periodically throughout grade school. The instructed students showed substantially more valid conceptions and fewer persistent misconceptions as evaluated in grades two, seven, ten, and twelve. The accumulated dataset showed the impact of early instruction, and the importance of tracking understanding over time. The researchers made use of concept maps transcribed from interviews with students. Quantitative data from the maps was measured using a scoring method of three areas of interest: relevant concepts, propositional linkages, and misconceptions. Analyses of the data reflected a series of complex changes in understanding over long periods of time. The longevity of misconceptions acquired early on was replete throughout. Furthermore, due to the discontinuity of instruction, there was an established trend in student learning to unsuccessfully integrate new knowledge into previously held cognitive structures.

The previous study shows that the concept map is a useful instrument to show the changes in student understanding in a longitudinal study. When coupled with interview, the narrative produced showed the unique learning pathways that students experienced. The following study reported on the ability of learners to successfully identify relationships during a shorter period of time during an earth/space science unit.

Briggs et al. (2004) conducted a case study in which they assessed the use of concept maps to convey the interdisciplinary concepts involved Mars exploration. CMEX Mars is an effort to create an extensive library of concept maps fully accessible to the public online. These concept maps, more than 100 in number, cover a diverse range of topics from planetary formation to astrobiology. The graphic organization of information allows learners to interact with the material by following links, displaying images, and viewing video files. The branching format of the content allows learners to see the 
connections between concepts. There were, however, limitations: a typical computer monitor measures 17 inches, which limits the number of concepts and the overall size of a map that may be displayed. Other ramifications included legibility and the 2 dimensional nature of the maps. The concept maps have been accessed primarily by educators. The programmers have altered their format in response to the users of the site to further serve the educational community. Mars exploration reached a peak in the public interest in recent years with the rover missions. CMEX Mars has been a collaborative effort with NASA and the Institute for Human and Machine Cognition. The researchers conclude that concept maps are a useful tool to depict Mars exploration, which has a place in many classrooms beyond Earth and space science. To date there have been strong efforts across disciplines to achieve the goals of Mars exploration.

Concept maps generated by students from scratch provide the opportunity to express dynamic relationships that provide evidence of understanding. Concept maps may resemble hierarchical organization or representations that are non-hierarchical or cyclic. Derbentseva and Safayeni (2004) report on the validity and reliability of concept maps to describe relationships. Their findings showed that students were able to utilize the structure of cyclic, or non-hierarchical, concept maps to identify valid propositions.

Derbentseva and Safayeni (2004) tested the propensity of students to describe dynamic relationships between concepts using either hierarchical or cyclic concept maps. A dynamic relationship included descriptions of changes in quality, quantity, or state respective of the two concepts linked in a proposition. The researchers administered blank concept maps, both hierarchical and cyclic, to 112 undergraduate students at the University of Waterloo. The students were asked to fill in the empty areas with concepts 
and cross-linking terms. Afterwards, the concept maps were analyzed. Each proposition, consisting of two concepts and a linking phrase, were individually assigned a "dynamic score" from $0-4$. There were 448 propositions scored in total. And efforts were taken to ensure scorer reliability with repeated blind test scoring, resulting in only $6 \%$ disparity. Results were analyzed with Wilcoxon-Mann-Whitney test for a pair wise comparison between hierarchical and cyclic concept maps. Analysis strongly supported the hypothesis that cyclic concept maps included more dynamic relationships than the hierarchical maps. In addition, the researchers compiled qualitative data on student preference between hierarchical and cyclic structure. The cyclic structure was strongly favored (84\% of students). It was described as "more intuitive," "makes more sense," "cycles clearly show how each concept is related to each other" (p. 7). The study found that the structural form of the map influenced the student content input. And, the cyclic structure lead to an increase in dynamic relationships.

\subsection{Summary}

Learning progressions are a powerful tool, but the assumption is that student learning increases in a step-wise fashion to mastery (Corcoran 2009, Shavelson 2009, Sneider et al. 2011, Paysnick 2010). An individualistic view of learning is in conflict with the assumption that understanding builds on conceptions with greater complexity as a student approaches mastery (Shavelson 2009). Attempts to address unique pathways to understanding rely upon variations in instruction and experimental design. Many of the reviewed studies produced findings that conclude learning is often meandering and takes place not only in the context of instruction, but is influenced by a learner's past 
experiences and their held misconceptions. Most students may not follow the step-wise growth in understanding described by Corcoran, Mosher and Rogat (2009).

Novak and Musandra (1997) found that misconceptions are persistent, over many years, and are often overlooked in instruction. As a result alternative conceptions that are seen as incorrect are actually an important step toward a student mastery of a concept (Sadler 1998). Catley et al. (2005) reported on the persistence of misconceptions surrounding evolution and used them to inform learning progressions. However, it would appear that misconceptions and alternative conceptions are natural steps in a learning progression for students as they strive to proficiency. As seen in the study conducted by Alvermann and Hague (1989), instruction that speaks to and warns against students' misconceptions renders effective results for students to achieve mastery of a concept.

The use of concept maps is an effective strategy to impress upon students the interactive nature of many of the concepts we teach (Briggs et al 2004). In particular a concept map that emphasizes a cyclic structure encourages student to see the connectedness that is a hallmark of science (Derbentseva and Safayeni 2004). Beyond the formidable utility of instruction concept maps are capable of depicting a student's thought process in ways that multiple choice and short answer assessments fall short. Concept maps breakdown assumptions about the isolation of concepts and allow students to literally connect their ideas.

As students move toward mastery of the concept, alternative conceptions influence their understanding and result in learning that meanders. "Progressions are not developmentally inevitable but dependent on instruction interacting with students' prior 
knowledge and new-knowledge construction; there is no one "correct order" for the progression. That is, progressions evolve in a succession of changes that take place simultaneously in multiple interconnected ways (Shavelson, 2009)." The application of concept maps in the validation of learning progressions is lacking in the literature. However, the literature shows that concept maps are ideal to depict how understanding of scientific concepts changes during instruction. Similar to Catley et al this study will define learning progressions students experience through the use of assessment and interviews. This study used concept maps to depict changes in student understanding, as well as interviews to provide narratives from a subset of students. Using both concept maps and interviews, changes in student understanding throughout a unit of study. 


\section{Chapter 3: Methods}

\section{Overview}

The research conducted was an inductive study of the changes in student understanding of a science concept during a unit of study and follows their individual pathways as they learn. The study was an attempt to answer the question: How does student understanding of a concept change throughout a unit of instruction? The intention is to support the theory of Learning Progressions. The independent variable of study was the treatment, and the dependant variable - learning pathways taken by each student - was the students' successive performance results on each of the concept map assessments. Students created a concept map prior to instruction, at critical junctures during the unit, and as part of their summative assessment. The presence of key propositional relationships aligned to current research on learning progressions in genetics (Duncan, Gogat, \& Yarden, 2009) as well as progressions within the Next Generation Science Standards (2013). Interviews were also conducted to provide selected participants opportunity to explain individual and recurring propositions, as well as compare and contrast their four concept maps from the previous six weeks.

Table 1: Experimental Design

\begin{tabular}{|c|c|c|c|c|c|c|c|c|c|c|c|}
\hline & $\begin{array}{l}\text { Pre- } \\
\text { instruction }\end{array}$ & $\begin{array}{l}\text { Critical } \\
\text { Juncture }\end{array}$ & $\begin{array}{l}\text { Critical } \\
\text { Juncture }\end{array}$ & $\begin{array}{l}\text { Critical } \\
\text { Juncture }\end{array}$ & $\begin{array}{l}\text { Summative } \\
\text { Assessment }\end{array}$ & $\begin{array}{l}\text { Post- } \\
\text { instruction }\end{array}$ \\
\hline $\mathrm{N}$ & $\mathrm{C}_{0} \mathrm{O}_{1}$ & $\mathrm{X}$ & $\mathrm{X}, \mathrm{O}_{1}$ & $\mathrm{X}$ & $\mathrm{X}, \mathrm{O}_{1}$ & $\mathrm{X}$ & $\mathrm{X}, \mathrm{O}_{1}$ & $\mathrm{X}$ & $\mathrm{O}_{1}$ & $\mathrm{X}$ & $\mathrm{O}_{2}$ \\
\hline
\end{tabular}

$\mathrm{N}$ - Nonrandomized participants

$\mathrm{O}_{2}-$ Student Interview

$\mathrm{C}_{0}-$ Concept Map Training $\mathrm{X}$-Instruction

$\mathrm{O}_{1}-$ Concept Map Assessment 


\subsection{Participants}

This study was conducted at the school to which I was assigned my student teaching internship. The test site was a K-8 science and math focus-option school in the metro area of Portland, OR. The student body is composed of 352 students and 17 full time teachers, as well as two half time teachers instructing technology and Spanish. A typical classroom comprises 30 students. The school is lead by a single administrator. Other supporting staff include one fulltime guidance counselor and rotating staff: school nurse and school psychologist.

The sample used for this study, from two eighth grade classes, was $59 \%$ male. A substantial portion of students (31\%) are identified TAG. Five students had an Independent Education Plan. 28\% are regarded as non- Caucasian; while 100\% speak English as the first language in their home. Information regarding socioeconomic status for individual students was unavailable. However, $11 \%$ of the entire population enrolled at the test site received free or reduced lunch.

In their previous year of science study, students have received a strong background in inquiry from their seventh grade science teacher. My mentor's philosophy of science education is heavily founded in constructivism as a means to self discovery. Their disciplinary focus was physical science at that grade. Students who have been promoted from sixth grade at the test site received earth science from an instructor who emphasizes nature of science and exploration in his instruction. Students were comfortable with concepts and vocabulary regularly used in the biology; many were very 
strong readers. The population at the test site was also very comfortable with the implementation of technology in instruction. The unit of study used for data collection was an introduction to genetics. The students had previously studied mitosis and meiosis. This unit began with Mendelian genetics, the construction of pedigrees, and then moved to molecular biology (structure of DNA and protein synthesis). The instruction was modeled after the Holt Biology Curriculum (2008) and supplemented with assessments and projects.

The majority of students that composed this group are exceptional learners and present few challenges to maintain a positive classroom culture. The culture of the classroom fostered intellectual conversation and peer collaboration in a way that supported learning outcomes. Students responded well to direct instruction as well as inquiry, however they exhibit the desire to be told the "answer."

During the time of the study, the researcher fulfilled a student-teacher role, not yet in control of instruction. The sample size was 55 individuals, a composite of two separate classes. All students participated in the concept map training, concept map preassessment, as well as the concept map assessments at critical junctures throughout the unit. Likewise, all students completed a final and fourth concept map as part of their summative unit test. Nine students were randomly assigned for interviews from three separate performance quantiles. The quantiles were assigned based on cumulative grades for the course. Names were then drawn from the three pools.

\subsection{Treatment}

Participants received preliminary instruction on the use and construction of concept maps. Instruction occurred during class, prior to the unit to be used during the 
course of this study. The students were shown several examples of student-generated concept maps. Discussion followed pointing out the strengths and weaknesses of each map: proper format, clarity, meaningfulness of relationships. In small groups, students constructed maps from a short list of words. Volunteers presented their maps, questions and comments from the class followed.

The following day, a pre-assessment concept map was created by the students prior to instruction to determine their previous knowledge of the content. A list of thirteen words was provided for each student. The list was carefully chosen by the researcher; input and face validity was provided by the mentor teacher. Each of the thirteen words aligned with the learning progression developed by Duncan, Rogat, and Yarden (2009). The terms addressed the key concepts covered by the unit of instruction the students experienced. The terms correspond with the Next Generation Science Standards (NGSS) (2013), specifically Disciplinary Core Ideas (LS.1A, LS.3A, LS.3B) associated with the topic: HS.Inheritance and Variation of Traits (p. 83). Students created concept maps prior to instruction, at two critical junctures throughout the unit, and culminated in a final summative unit test including a concept map portion. The critical junctures for this unit occurred just after instruction related to one of the four key propositions was completed and followed by a performance task. Once the students were assessed for understanding, ideally correcting alternative conceptions, a concept map was administered.

According to Godwin and Novak (1984), "a concept map is a schematic device for representing a set of concept meanings embedded in a framework of propositions" ( $\mathrm{p}$. 15). They work to clarify students understanding of concepts systematically and may 
provide a sort of visual road map that displays nonlinear associations a learner potentially makes to assert their understanding of a topic. To facilitate an efficient analysis of the students' concept maps, a learning profile was compiled for each student from each of the four concept maps. These learning profiles allowed a comparison between the students. Below is an example of a learning profile developed based on the unit of instruction and what the researcher thought the students might produce based on the learning progressions presented by Duncan, et al 2009 and the standards in the NGSS. This pattern was expected because the propositions were taught in numerical order. In addition, it was thought that once students demonstrated their understanding of a concept, they would continue to demonstrate this understanding throughout the unit. The first row of the profile is left blank since the first concept map was given prior to any instruction. Finally, it was predicted that most of the students would demonstrate clear understanding of all propositions by the end of the unit. Each of the cells filled with color in the above table correspond to the presence of a valid proposition shown in a student's concept map.

\begin{tabular}{|r|r|l|l|l|}
\hline \multicolumn{5}{|c|}{ Learning Profile } \\
\hline Proposition: & 1 & 2 & 3 & 4 \\
\hline Concept Map 1 & & & & \\
\hline Concept Map 2 & & & & \\
\hline Concept Map 3 & & & & \\
\hline Concept Map 4 & & & & \\
\hline
\end{tabular}

figure 1 Example Learning Profile

The unit of instruction used for the treatment was an introduction to genetics. The unit began with an overview of Mendelian genetics and moved to the structure and function of DNA. The unit culminated with transcription and translation of genes. The students experienced various teaching strategies throughout the unit, including direct instruction, problem based learning, projects, supplemental videos, and labs to relay the 
content. Supplemental to instruction, students utilized the textbook for the course under the direction of the teacher with daily handouts and worksheets to convey the material covered in each section. These assignments were checked for accuracy by peers almost daily, and those scores were recorded to track student performance. Also, throughout the unit, concept maps were administered by the researcher to check for conceptual understanding of the material using the aforementioned list of thirteen terms. Once the students reached a critical juncture in instruction, the students were administered a concept map in order to check for changes in understanding of the material just previously covered. The critical junctures the concept maps were administer were moments in time during the unit where instruction moved on to another major topic; at these times it was apropos to formatively assess the students' mastery of the covered material as well as their changing understanding of genetics as a subdiscipline of biology and subtopics not yet covered, but alluded to during instruction.

The students began the unit with coverage of Mendelian genetics and linked the abstract concepts of heredity science to pedigrees (proposition 1), Table \#2. The students were presented with the problem: "What would happen if two green, fire-breathing, and neck-spiked dragons fell in love, got married, and had babies? What would their baby dragons look like?" This problem based learning captured students understanding of numerous concepts in heredity science, where they were posed with the challenge of interbreeding imaginary creatures with defined characteristics (phenotypes) whose alleles (genetics) were known. Among the standard dihybrid crosses, students were expected handle the challenge of sex linked traits as well. Once their offsprings' traits, or the frequency of offspring traits amongst a small sample, were calculated the students created 
an artistic poster representation of the pedigree complete with punnett squares. The students were given information, a brief introduction in class, and approximately three weeks to complete the project, at this time the second of four concept maps was administered. The first was a pre-assessment probe. With the exception of the final concept map, all were formative assessments. The concept map for this critical juncture corresponded with the summative assessment for this chapter in the textbook, but the student performance on this concept map was not factored into their overall grade for the course.

Following Mendelian genetics, the students covered the structure and function of DNA, proposition 2 (see Table \#2). During this section of the unit, the students learned about the molecular subunits of deoxyribonucleic acid and began to understand the scales associated with the molecule residing in each nucleated cell. Students had, prior to this unit, studied the organization and function of eukaryotic and prokaryotic cells - where each organelle and major structure was described. Also, cell division was subsequently covered. After cell structure and function, students covered cell division (mitosis) and gamete production (meiosis). These two processes are very different from one another, however the Holt curriculum (2008) covered both mitosis and meiosis in tandem, as is the convention.

Following the structure and function of DNA, students were introduced to the topic of protein synthesis(. Students again followed the Holt (2008) textbook with daily readings. Direct instruction, as well as supplemental videos, high lighted key elements and events from the transcription of DNA to mRNA, and the subsequent translation of mRNA into proteins. The performance task set to the students to assess their 
understanding was a paper modeling activity, "Recipe for Proteins.". Students were given feedback prior to their summative unit test.

Below is a table that shows other essential components of instruction that took place over the course of the unit. For each proposition there were associated lectures, labs, and activities.

Table 2: Propositions \& Associated Classroom Activities

\begin{tabular}{|c|c|}
\hline $\begin{array}{l}\text { Order in Which Propositions } \\
\text { were Taught }\end{array}$ & $\begin{array}{l}\text { Classroom Activities Used for } \\
\text { Instruction }\end{array}$ \\
\hline \multirow{3}{*}{$\begin{array}{l}\text { Proposition 1: The gene variants } \\
\text { differ in their nucleotide sequence } \\
\text { resulting in different or missing } \\
\text { proteins that affect our } \\
\text { phenotype. }\end{array}$} & Lecture: Mendellian Genetics \\
\hline & $\begin{array}{l}\text { Lab: modeling inheritance using } \\
\text { Punnett squares }\end{array}$ \\
\hline & Project: Dragon breeding poster \\
\hline \multirow{3}{*}{$\begin{array}{l}\text { Proposition 2: Chromosome sets } \\
\text { are randomly assorted into } \\
\text { gametes through the process of } \\
\text { meiosis. }\end{array}$} & Lecture: Meiosis \\
\hline & Lab: Crossing over with beads \\
\hline & Activity: Meiosis Square Dance \\
\hline \multirow{3}{*}{$\begin{array}{l}\text { Proposition 3: Genes are } \\
\text { nucleotide sequences that make } \\
\text { up segments of the DNA } \\
\text { molecule. DNA molecules make } \\
\text { up chromosomes that make up } \\
\text { our genome. }\end{array}$} & $\begin{array}{l}\text { Lecture: Structure \& function of } \\
\text { DNA }\end{array}$ \\
\hline & Activity: Blueprint of Life \\
\hline & Lab: Strawberry DNA extraction \\
\hline \multirow{3}{*}{$\begin{array}{l}\text { Proposition 4: The genetic code } \\
\text { is translated into a sequence of } \\
\text { amino acids that makes up the } \\
\text { structure of proteins. }\end{array}$} & $\begin{array}{l}\text { Lecture: Transpiration and } \\
\text { translation }\end{array}$ \\
\hline & Lab: Lego Protein Synthesis \\
\hline & Project: Recipes for proteins \\
\hline
\end{tabular}

The following table outlines the timing of concept maps with dates and what instruction took place in the interim. The table shows that the first concept map was administered prior to any instruction. The second followed instruction on proposition 1 , Mendelian Genetics and Hereditary Science. The third concept map followed instruction on propositions $2 \& 3$, DNA replication \& meiosis and structure \& function of DNA, 
respectively. And the fourth was part of a summative assessment after instruction had been given on all four propositions.

Table 3: Concept Map Timing

\begin{tabular}{|c|c|c|c|c|c|c|}
\hline $\begin{array}{l}\text { CMap 1 } \\
\text { (Pre- } \\
\text { instruction) }\end{array}$ & \multirow{2}{*}{$\begin{array}{l}\text { Mendelian } \\
\text { Genetics and } \\
\text { Hereditary } \\
\text { Science }\end{array}$} & $\begin{array}{c}\text { CMap } \\
2\end{array}$ & \multirow{2}{*}{$\begin{array}{c}\text { DNA } \\
\text { replication } \\
\& \text { meiosis; } \\
\text { structure \& } \\
\text { function of } \\
\text { DNA }\end{array}$} & $\begin{array}{c}\text { CMap } \\
3\end{array}$ & \multirow{2}{*}{$\begin{array}{l}\text { Protein Synthesis, } \\
\text { transcription \& } \\
\text { translation }\end{array}$} & $\begin{array}{l}\text { Camp Post } 4 \\
\text { (Summative } \\
\text { assessment) }\end{array}$ \\
\hline $02 / 25 / 13$ & & $\begin{array}{c}03 / 15 / \\
2013\end{array}$ & & $\begin{array}{c}03 / 25 / \\
2013\end{array}$ & & $04 / 10 / 2013$ \\
\hline
\end{tabular}

\subsection{Instruments}

Concept maps Each participant included in the study constructed four concept maps at different points throughout the unit of instruction. A pre-assessment concept map was completed by each student, two at critical junctures of instruction, and a final concept map was included in their summative unit test. The students were allowed to construct their maps in a free form on a blank sheet of paper; they were provided with a list of thirteen words. The free form encouraged students to organize relationships in a cyclically instead of hierarchically. Markham and Mintzes (1994) sought to establish concurrent validity of concept maps by comparing maps generated from biology majors and non-majors. Their results showed evidence for concept maps as a research and evaluation tool. "Concept maps can be reliably scored despite the complex judgments involved in assessing the quality of students' propositions" (Ruiz-Primo, Shavelson, \& Shultz, 1997). Interrater reliability was attempted with two observers scoring concept maps independently. 48 propositions were assessed with $98 \%$ agreement between the two scorers. 
Interviews A small subset of students was selected for short (10-15 min.) interviews. Interviews took place at the end of the unit; the interviewees were nine students selected at random within three performance quantiles determined by their cumulative grade in the class at the time. The interviews consisted of open-ended questions intended to elicit a narrative from the student. Each student was presented with all four of their concept maps at the time of interview. The concept maps were covered by plastic sheets so that students could annotate them during interviewed without altering the original.

\subsection{Procedure}

The proposed study took place at a science-math focus option school in Portland . Prior to the introduction of a new unit of study, the researcher conducted a fifty-five minute session designed to introduce participants to concept maps. The unit of instruction was taught by the cooperating teacher. At critical junctures of the unit, participants will construct concept maps. The maps were collected and an analysis of individual learning gains, as well as population learning gains were calculated. The concept maps were assessed to develop a learning profile for each student. Then each learning profile was examined to determine patterns in the students' learning profiles and similarity to the predicted learning profile, figure 1 . At the end of the unit, nine students were interviewed to provide a narrative regarding changes in understanding. Three students were randomly selected from each of three quantiles representing high, middle, and low performing students based on academic standing in the course. 


\section{Chapter 4: Results}

Students created concept maps at four points throughout instruction of unit on genetics. Each of the concept maps was scored for the presence of four key propositions: 1.) gene variants differ in their nucleotide sequence resulting in different or missing proteins that affect our phenotype; 2.) chromosome sets are randomly assorted into gametes through the process of meiosis; 3.) genes are nucleotide sequences that make up segments of the DNA molecule, DNA molecules make up chromosomes that make up our genome; and 4.) the genetic code is translated into a sequence of amino acids that makes up the structure of proteins. A proposition is represented in a concept map by linking two concept nodes by a connecting line which has a brief descriptor associate with the relationship between the concepts. The four propositions are presented above in the sequence they were taught.

The total sample size for the study group was 55 eighth grade high school-level biology students. Concept maps from each participant were scored, indicating the presence or absence of a valid proposition that aligned with four key ideas. A listing of the assessed propositions can be found beneath the chart on the following page. Figure 3 is a sample of the learning profiles created by the researcher. Each student's presence or absence of a valid proposition 1-4 is shown for each of their four concept maps color coded in an individual profile.

Each student profile was compared to the following exemplar profile, figure 1. The profile below represents what the researcher expected to see based on the order the four propositions were taught. It was reasoned that once a student presents a valid proposition that it would continue to appear in future concept maps. 


\begin{tabular}{|r|l|l|l|l|}
\hline \multicolumn{5}{|c|}{ Learning Profile } \\
\hline Proposition: & 1 & 2 & 3 & 4 \\
\hline Concept Map 1 & & & & \\
\hline Concept Map 2 & & & & \\
\hline Concept Map 3 & & & & \\
\hline Concept Map 4 & & & & \\
\hline
\end{tabular}

figure 1 Expected Learning Profile

The learning profiles of the students did not resemble the expected profile. Proposition 3 had a high degree of occurrence in the first concept map (40\%), indicating that students had some prior knowledge entering the unit. Students did not show retention in the acquisition of new knowledge. Some propositions were valid in early concept maps only to disappear in later versions. However, by the end of the unit, students showed the highest frequency of valid propositions with the exception of proposition 1 which decreased slightly. six profiles were selected at random from the same three performance quantiles as the interviewees and are shown below in figure 2.

Low:

\begin{tabular}{|r|c|c|c|c|}
\hline \multicolumn{5}{|c|}{ Student 820 } \\
\hline Proposition: & 1 & 2 & 3 & 4 \\
\hline Concept Map 1 & & & & \\
\hline Concept Map 2 & & & & \\
\hline Concept Map 3 & & & & \\
\hline Concept Map 4 & & & & \\
\hline
\end{tabular}

\begin{tabular}{|r|r|l|l|l|}
\hline \multicolumn{5}{|c|}{ Student 803 } \\
\hline Proposition: & 1 & 2 & 3 & 4 \\
\hline Concept Map 1 & & & & \\
\hline Concept Map 2 & & & & \\
\hline Concept Map 3 & & & & \\
\hline Concept Map 4 & & & & \\
\hline
\end{tabular}


Medium:

\begin{tabular}{|r|l|l|l|l|}
\hline \multicolumn{5}{|c|}{ Student 844 } \\
\hline Proposition: & 1 & 2 & 3 & 4 \\
\hline Concept Map 1 & & & & \\
\hline Concept Map 2 & & & & \\
\hline Concept Map 3 & & & & \\
\hline Concept Map 4 & & & & \\
\hline
\end{tabular}

\begin{tabular}{|r|l|l|l|l|}
\hline \multicolumn{5}{|c|}{ Student 839 } \\
\hline Proposition: & 1 & 2 & 3 & 4 \\
\hline Concept Map 1 & & & & \\
\hline Concept Map 2 & & & & \\
\hline Concept Map 3 & & & & \\
\hline Concept Map 4 & & & & \\
\hline
\end{tabular}

High:

\begin{tabular}{|r|l|l|l|l|}
\hline \multicolumn{5}{|c|}{ Student 807 } \\
\hline Proposition: & 1 & 2 & 3 & 4 \\
\hline Concept Map 1 & & & & \\
\hline Concept Map 2 & & & & \\
\hline Concept Map 3 & & & & \\
\hline Concept Map 4 & & & & \\
\hline
\end{tabular}

\begin{tabular}{|r|r|l|l|l|}
\hline \multicolumn{5}{|c|}{ Student 823 } \\
\hline Proposition: & 1 & 2 & 3 & 4 \\
\hline Concept Map 1 & & & & \\
\hline Concept Map 2 & & & & \\
\hline Concept Map 3 & & & & \\
\hline Concept Map 4 & & & & \\
\hline
\end{tabular}

figure 2 Student Profiles

The overall percentages of students who presented valid propositions are shown in the Table 3 and figure 3 below. Concept Map \#1 was a pre-assessment probe given before instruction, \#2 and \#3 were given at critical junctures, and \#4 was part of a summative unit test. 
Table 4 Percentages of Valid Propositions Overall

\begin{tabular}{|l|c|c|c|l|}
\hline & Concept Map \#1 & Concept Map \#2 & Concept Map \#3 & Concept Map \#4 \\
\hline Proposition 1 & $2 \%$ & $29 \%$ & $42 \%$ & $36 \%$ \\
\hline Proposition 2 & $6 \%$ & $0 \%$ & $9 \%$ & $13 \%$ \\
\hline Proposition 3 & $40 \%$ & $31 \%$ & $50 \%$ & $60 \%$ \\
\hline Proposition 4 & $0 \%$ & $0 \%$ & $15 \%$ & $55 \%$ \\
\hline
\end{tabular}

The chart in figure 3 shows the changes in frequency of students presenting valid propositions. The data show that not all propositions increase in frequency as more instruction is given.

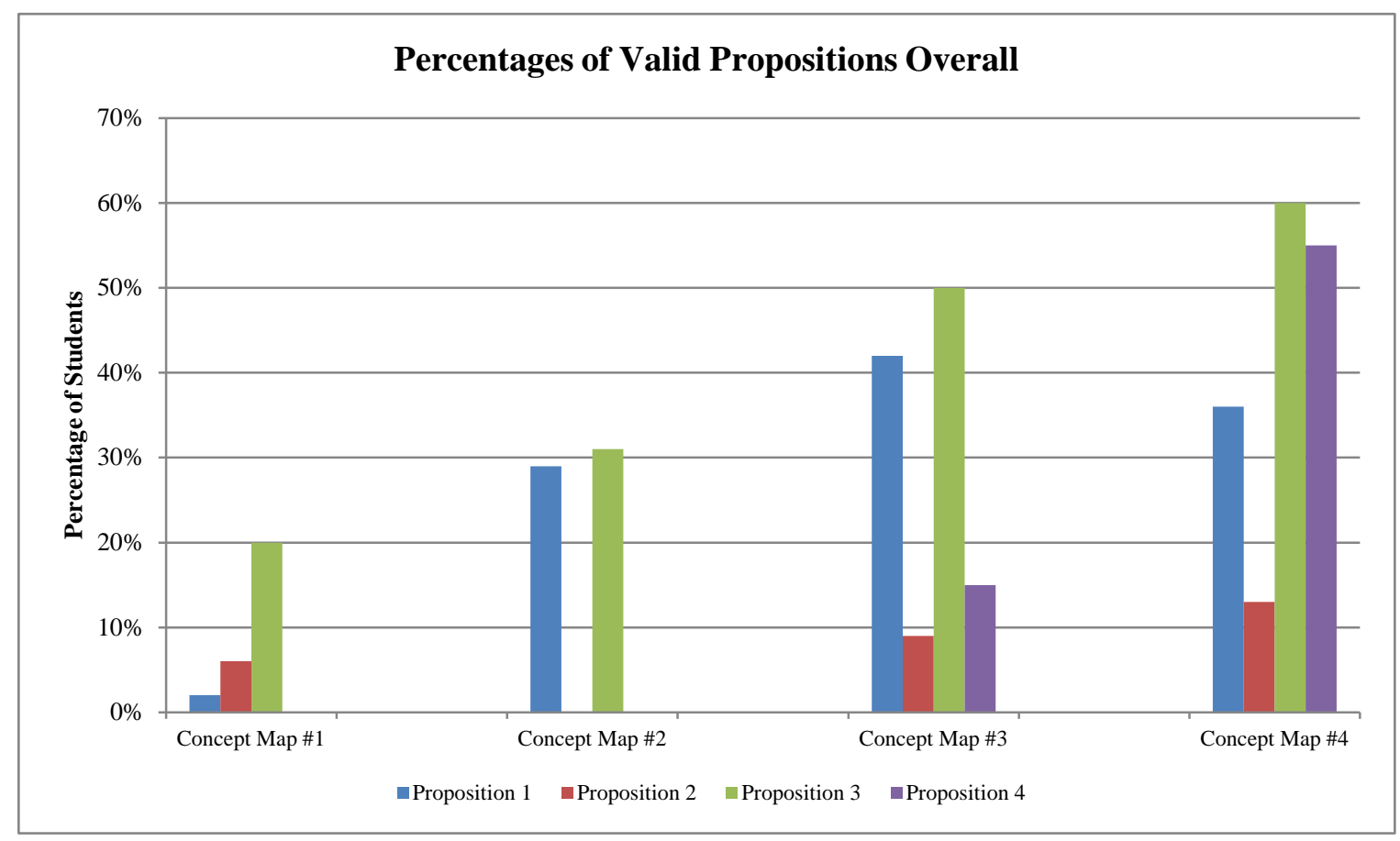

figure 3 Percentages of Valid Propositions Overall

Figure 4 lists the propositions including their associated color code to show how the frequency of students presenting them in each concept map changes over time. 
Proposition 1: (blue) The gene variants differ in their nucleotide sequence resulting in different or missing proteins that affect our phenotype.

Proposition 2: (red) Chromosome sets are randomly assorted into gametes through the process of meiosis.

Proposition 3: (green) Genes are nucleotide sequences that make up segments of the DNA molecule. DNA molecules make up chromosomes that make up our genome.

Proposition 4: (purple) The genetic code is translated into a sequence of amino acids that makes up the structure of proteins.

figure 4 List of Propositions

Interview Results

Interviews were conducted during class time. Students were taken out of the classroom; the researcher and the interviewee were able to communicate one-one-one.

Participants were given their four concept maps to reference and interact with using plastic protective sheets and dry-erase markers. The following quotations represent common themes from interviewees.

Question: What do you notice about the similarities and differences between the four concept maps?

Responses: "I used less connections on the earlier maps." "My maps become more correct over time." I became less wordy and more to the point." "Words [that are in common] are connected differently in different maps." "The last concept map is my favorite. I felt more confident drawing them and making connections between concepts."

Question: Can you pick out a relationship and talk about how it changed from one map to the next?

Responses: "I tried to add more concepts to DNA and genes in later maps." "It looks like some relationships disappeared and then cam back again." "My connections between gamete and probability was weird." "I connected more things to it"

Question: What lessons or activities helped you the most to understand genetics? Responses: "I don't remember." "Group work." "The Dragon Pedigree Project." "The video you showed from Harvard Biomedical really helped me understand protein synthesis." "Even though the Recipe for Proteins was really confusing it helped in the end." "Being taught about Punnett squares." 
Question: How would you describe the way your understanding about genetics changed?

Responses: "It almost seems like the more I learned, the more confused I became. But, I tied it together in the end." "I was able to use things that I learned before, and I used that to help me make sense of what we learned in this unit." "I made some mistakes along the way, some of my relationships aren't really true." "Even though we took the unit test already, there are things we've learned since that help me understand genetics. Stuff like mutations." 


\section{Chapter 5: Discussion}

This study was an attempt to describe the learning progressions of students as they occurred throughout a unit of instruction. The prevailing view of learning progressions is a linear escalation of complexity over time (Corcoran 2009). An alternative view is that learners do not progress in a direct fashion, adding more and more complex ideas, but access new knowledge though a network of relationships where concepts are connected through networks akin to a roadmap (Shavelson, 2009, Salinas, 2009).

The results of this study showed that student understanding did increase over time. Figure 2 shows a positive correlation to student learning over the population as a whole. Overall class learning progressions increase in frequency of mastery, but more importantly individual profiles show pathways unique to the learner. When the data were disaggregated to the student level as represented by figure 4 it became clear that students' understanding wandered, picking up apparent mastery of content - only to drop it in subsequent concept maps. The 55 student profiles that were compiled and analyzed were all very dissimilar from the expected learning profile, figure 1.

Student profiles were very unique among each other, very characteristic of the student and the context of their learning. Student retention of valid propositions once they were presented in early concept maps was inconsistent. Valid propositions had a tendency to appear, disappear, and reappear for many students. Some students had some prior knowledge of the subject. In particular, proposition \#3 (which was concerned with the structure and scale of the DNA molecule s well as its function as information storage) was shown in high frequency in early concept maps prior to instruction on this specific 
topic. During interviews students commented on changes in thinking that seemed to lead to confusion about topics once they received more instruction. It appeared that more information, instead of always increasing clarity, for some created alternative conceptions.

This study found that student understanding of genetics followed pathways that were not predictable. Valid propositions appeared only to vanish in subsequent renditions. Students were able to notice this trend themselves in examination of their concept map progressions during interviews. Several students seemed to progress in understanding thought the first three concept maps only to completely miss the unifying concepts in their summative assessment. The change in understanding that students showed in their concept maps throughout this unit was often not progressive; however interviews showed an overwhelming ability of all students to revisit the material intelligently and discuss their learning thoughtfully.

A proposition that many students struggled to represent accurately was proposition 3: Genes...It was apparent that misconceptions about scale were prevalent at the beginning of instruction. It was unclear to some students that genes are found on DNA, and not vice versa. For those students that this was an obstacle, analysis of the concept maps and interviews showed that thoughts about DNA were mired in its status as a molecule. And, to date, most students' experience with molecules is that they are small - not the six foot long tangle housed within a microscopic space. Therefore the conception of genes is that they are somehow separate from the DNA strand and not a segment along its length.

Later in the unit, while studying protein synthesis, more students were capable of the rectifying this misconception. By kinesthetically modeling complementary base pairs 
of mRNA and amino acids carried by tRNA in "Recipe for Proteins" students gained a better sense of scale. Also, supplemental videos showing the storage of DNA wrapped around histone proteins conveyed the sheer size of the DNA molecule with computer animation. This misconception has also been documented by Driver (2004). Some implications for future practice include establishing a sense of scale, but also relevance for genetics with the students. Once scale and functionality were established for the long list of molecular players, students were better equipped to grasp the content. Interactive scaling applets may be useful in this regard, such as those developed by Huang (2012).

Assessments composed of multiple choice items revealed that some students were more adept at this style of evaluation in comparison with concept maps. Novak and Gowin (1984) showed that higher order thinking skills are involved in concept maps. They emphasize relationships between concepts rather than memorization of facts.

Possible limitations to the study were largely threats to generalizability. The population from which the researcher derived his sample group is a science and math focus-option school. While the depth of metacognition and the astute attention the students offered was informative, it may not be representative of their adolescent peers who also study biology. The curriculum utilized by the study site is not in full alignment with the upcoming Next Generation Science Standards nor does it reflect the current research addressing learning progressions in science. As such, the sequence in which concepts were taught was not in sync with the learning progressions that yielded the propositions assessed. Also, the setting differed for the fourth and final of the concept maps; it was used as a component of their summative assessment for the unit. The students were administered a 36 item test, 32 multiple choice and 4 short answer. Upon 
completion the students were supplied with the same 13 item word bank and a blank sheet of paper. The standard thirty minutes was allotted. It is possible that students who experience test anxiety were inhibited by the notion their final concept map would affect their grade.

According to Corcoran (2009) an ideal learner profile, in the style of this research, would show that students increased their mastery one proposition at a time until the final concept map, where all the propositions were represented. No student exhibited this ideal pattern in their profile. Shavelson (2009) warned of the possibility of that specific teaching styles and sequences of instruction would validate certain learning progressions. This study showed the converse of that suspicion. The instruction rendered to these students, the prior knowledge they brought, and the alternative conceptions they formed did not fit the learning progression proposed by Duncan, Rogat, and Yarden (2009).

The concept maps clearly showed how student understanding changed measured against Duncan, Rogat, and Yarden's learning progression (2009). The changes in understanding that the students experienced was intimately linked to the context in which they were taught. The students taught in this sample showed gains in learning that reflected the teaching sequence of the propositions and the types of activities and assessments that were utilized. The learning progression created by Duncan, Rogat, and Yarden does not align with what the students experienced since they were taught in a sequence that varied from theirs. This strengthens Shavelson's claim that learning progressions are indeed context dependent and that validating them is difficult. Furthermore, the endeavor to validate learning progressions is susceptible to data fitting. 
Given that students will develop understanding dependent upon the context of their learning, i.e. the sequence in which they were taught.

Shavelson's (2009) challenge to the conventional interpretation of learning progressions is worthy of further research. Even the limited scope of this study provided support to the nonlinear learning progressions of students studying genetics. Implications for learning progressions are vast. Learning progressions affect our assessment of student performance, their ability to respond to instruction, as well as teaching sequences appropriate to their development. A more individualized approach to learning progressions validates problem-based and performance assessment. Duncan, Rogat, and Yarden (2009) agree that performance tasks are an important part of assessing student understanding, and learning progressions would be augmented with the inclusion of performance tasks. An accurate learning progression would allow any teacher to anticipate misconceptions, address shortfalls, and use corrective best practices to suit the needs of the population taught.

The researcher regards measuring changes in student understanding a worthwhile endeavor. The use of concept maps was ideal to show deeper insight into the thinking of students, much more so than multiple choice or short answer items. Using multiple concept maps provided a narrative of the developing student ideas as they were given a unit of instruction. The testimonies of the interviewed students gave were rich with metacognitive observations made by the students themselves. They were able to speak about their thinking changing regarding the topics we covered. Providing the concept maps for the interviewee to interact with allowed students to follow their own progression with physical maps they created themselves. 
Students' changes in understanding cannot be decoupled from the context of their learning. Therefore, the future validation of learning progressions must take into account factors that are implicit in teaching. Factors such as prior knowledge, the learning environment, assessment, student/teacher relationship, and many others have an effect on the progression of learning experienced by all students. Even with so many influences, it is still important work to move forward and find the most effective means of teaching. 


\section{References}

Alvermann, D. E. , \& Hague, S. A. (1989). Comprehension of counterintuitive science text: effects of prior knowledge and text structure. Journal of Educational Research. 82(4), 197-202.

Briggs, G., Shamma, D. A., Canas, A. J. Carff, R., Scargle, J., \& Novak, J. (2004). Concept Maps applied to Mars exploration public outreach. [Presented at the First Int. Conference on Concept Mapping].

Corcoran, T., Mosher, F., \& Rogat, A. (2009) Learning Progressions in Science: An Evidence-based Approach to Reform

Duncan, R.G., Rogat, A., \& Yarden, A. (2009). A Learning Progression for deepening students' understandings of modern genetics across the 5th-10th grades. Journal of research in Science Teaching, 46 (6), 655-674.

Eberle, F., \& Greeley P. (2008). Formative assessment probes: a look at how probes uncover conceptual connections. Science and Children, 45(5), 50-54.

Makham, K, Minzes J, \& Gail, J. (1994). The Concept Map as a Research and Evaluation Tool: Further Evidence of Validity. Journal of Research in Science Teaching, 31(1), 91-101.

National Assessment Governing Board (NAGB) (2005, November 4). Science NAEP 2009: Science Framework for the 2009 National Assessment of Educational Progress.

Novak, J.D., \& Godwin, B.D. (1984) Learning How to Learn. Cambridge: Cambridge University Press.

Novak, J. D., \& Musandra, D. (1991). A twelve-year longitudinal study of science 
concept learning. American Educational Research Journal, 28(1), 117-153.

National Research Council (NRC) (2012). A Framework for K-12 Science Education:

Practices, Crosscutting Concepts, and Core Ideas. Washington, DC: The National Academies Press.

Paysnick, R. (2010). Finding learning beneath the surface: monitoring student progress with scientific learning progressions. Science Scope. 34(2), 69-76.

Ruiz-Primo, M.A., Shavelson, R.J., \& Shultz, S.E. (1997) On the Validity of Concept Map-Base Assessment Interpretations: An Experiment Testing the Assumption of Hierarchical Concept Maps in Science. Los Angeles, Ca : National Center for Research on Evaluation, Standards, and Student Testing (CRESST), Center for the Study of Evaluation (CSE), Graduate School of Education \& Information Studies, University of California, Los Angeles

Sadler, P.M. (1998). Psychometric models of student conceptions in science:

Reconciling qualitative studies and distractor-driven assessment instruments. Journal of Research in Science Education. 35 (3), 265-296.

Shavelson, R. J. (2009). Reflections on learning progressions. [Presented at the Learning Progressions in Science (LeaPs) Conference]. 1-12.

Sneider, C., Bar, V., \& Kavanagh, C. (2011). Learning about seasons: a guide for educators and curriculum developers. Astronomy Education Review, (10), 010103-1-010103-22. 